\author{
Andreja Legan Ravnikar \\ Inštitut za slovenski jezik Frana Ramovša ZRC SAZU, Ljubljana
}

\title{
K problematiki vpliva stičnega jezika - nemščine na semantične spremembe in stilno vrednost najstarejše slovenske knjižne leksike (16. stoletje)
}

V članku smo ugotavljali, katere pomenske spremembe so doživljali prevzeti leksemi v primerjavi z izhodiščnimi nemškimi v procesu integracije v slovenski jezikovni sistem in knjižni jezik 16. stoletja. Spremembe so se dogajale tudi v pomenski strukturi domačih knjižnih leksemov, ki so pod vplivom prevodnih predlog (predvsem) nemških verskih reformatorjev poimenovali nove predmete, pojave in pojme. Tretji problem se nanaša na problematiko vpliva tujejezične leksike na stilno zaznamovanost prevzetih in domačih leksemov v knjižni slovenščini 16. stoletja. Potrdilo se je, da je semantični razvoj v večpomenskost tako pri prevzetih kot domačih leksemih eden od pomembnih razlogov za številčno skromen obseg slovenske knjižne leksike 16. stoletja (nekaj nad 22.000 besed). Pomenski razvoji leksemov, uporabljenih v knjižnem jeziku 16. stoletja, kažejo tudi na ubesedovalne zmožnosti slovenskih protestantskih piscev in izrazno moč slovenskega jezika.

The paper addresses the changes in meaning of loanwords compared to the meaning of German lexemes during the process of their integration into the Slovenian language system and the $16^{\text {th }}$ century literary language. Another change occurred in the semantic structure of native literary lexemes, which referred to new objects, phenomena and concepts under the influence of translations of the works of (mostly) German religious reformers. The third problem is the influence of the donor language on the stylistic markedness of loanwords and native lexemes in the $16^{\text {th }}$ century literary Slovene. It was confirmed that the semantic development towards ambiguity in native lexemes as well as in loanwords became one of the most important reasons for a relatively modest thesaurus of the $16^{\text {th }}$ century Slovenian literary lexica (just above 22.000 words). The semantic development of the $16^{\text {th }}$ century literary lexemes show the expressive abilities of Slovene Protestant writers and the expressive potential of the Slovene language.

\section{Uvod}

Pri leksikografskem delu za Slovar slovenskega knjižnega jezika 16. stoletja ${ }^{1}$ se zaradi neposrednih in posrednih jezikovnih stikov slovenščine z nemščino srečujemo

${ }^{1} \mathrm{~V}$ pripravi je prvi zvezek (A-D) in spletna verzija Slovarja slovenskega knjižnega jezika 16. stoletja. Nastaja na podlagi analize vsega občnoimenskega besedja v vsakokratni rabi, ki je izpričano v jezikovnem korpusu slovenskih protestantskih piscev 16. stoletja. 
s problematiko, ki jo znotraj jezikoslovne znanosti preučuje kontaktno jezikoslovje. S pomočjo njegovih teoretičnih izhodišč in raziskovalnih metod želimo ugotoviti, katere pomenske spremembe so doživljali sprejeti leksemi v primerjavi z izhodiščnimi nemškimi v procesu integracije v slovenski jezikovni sistem in knjižni jezik 16. stoletja. Kot drugo nas zanima, ali so se spremembe dogajale tudi v pomenski strukturi že znanih domačih leksemov, ki so pod vplivom (predvsem) prevodnih predlog nemško pišočih reformatorjev poimenovali novo predmetnost, pojave in pojme. Tretji problem se nanaša na vprašanje vpliva tujejezične leksike iz prevodnih predlog na stilno zaznamovanost knjižnih leksemov v 16. stoletju. Glede na analizirani gradivski obseg obravnave, ki zajema slovarske sestavke z iztočnicami od A do vključno D, je vpliv nemščine na pomenske spremembe knjižnih leksemov prikazan vzorčno in orisno, za prikaz obsega tovrstnih sprememb in njihove neposredne odvisnosti od nemščine kot stičnega jezika oz. jezika prevodnih predlog $\mathrm{v}$ 16. stoletju pa bi bilo raziskavo potrebno razširiti. Hkrati se zavedamo, da vpliva nemščine ne smemo poenostavljati, saj je bila na podlagi primerjalnih analiz slovenskih besedil s prevodnimi predlogami pomensko neodvisna raba tako prevzetih kot domačih besed večkrat dokazana.

Sprejem jezikovnih prvin iz jezika dajalca (iz nemščine ali z njenim posredovanjem predvsem iz klasičnih jezikov) v jezik prejemnik (slovenščino) je potekal na vseh ravninah jezikovnega sistema, predvsem prek govornih stikov pripadnikov različnih jezikov, na kar so vplivale večstoletne zgodovinske, politične, geografske in kulturne okoliščine, ${ }^{2}$ ter v knjižnem jeziku 16. stoletja tudi s pisnimi stiki - prek branja, prevajanja in prirejanja tujejezičnih verskih besedil. V kontaktnem jezikoslovju obstajata dva osnovna mehanizma jezikovnega prevzema: pri importaciji gre za sprejemanje tujih jezikovnih prvin iz jezika dajalca v jezik prejemnik, pri substituciji pa za njihovo zamenjavo na vseh jezikovnih ravninah s podobnimi prvinami, ki so značilne za jezik prejemnik (Filipović 1986: 68). Zaradi procesov transfonemizacije (fonemi jezika dajalca se zamenjajo s sorodnimi iz jezika prejemnika) in transmorfemizacije, ${ }^{3}$ transmorfologizacije in transderivacije ${ }^{4}$ prevzete besede v knjižnem jeziku 16. stoletja izkazujejo variacije glede na zapis, izgovor, izmenjavo fonemov, morfemov, različne stopnje prilagoditev oblikoslovnih kategorij, tvorbenih modelov in podomačevanja obrazilnih morfemov (Legan Ravnikar 2012: 134-142, 2013: 131-133, 2014: 72-80).

${ }^{2}$ V knjižni izdaji je različne sociolingvistične okoliščine, ki so bile razlog za močen, tisočletni vpliv nemščine tako na govorjeni jezik (dialekte) kot rokopisno tradicijo in knjižni jezik (od najstarejše knjižne slovenščine v 16. stoletju do konca 18. oz. začetka 19. stoletja), izčrpno povzel D. F. Reindl 2008: 1-14.

${ }^{3}$ Filipović 1986: 69-76, 119-152, prim. tudi: Hock 1991: 390-397, Newerkla 2004: 4065, Riehl 2004: 80-83, 89-93.

${ }^{4}$ Gl. Ajduković 2004b: 144-167, 178-190, Hock 1991: 400-404. 


\section{Pomenske spremembe prevzetih besed iz nemščine}

Rezultat jezikovnega stika na semantični ravni, ki poteka v dveh oz. treh fazah transsemantizacije, je adaptacija danega pomena izhodiščne tuje besede (t. i. modela) iz jezika dajalca v prevzeto besedo (t. i. repliko) v jeziku prejemniku. ${ }^{5}$ Pomenski prevzem vedno poteka $v$ danem besedilnem okolju, zato se v jezik prejemnik naenkrat sprejme le eden, aktualni pomen. Proces semantične prilagoditve prevzete besede se glede na obseg pomena uresničuje na tri načine: 1. pomenska struktura prevzete besede je povsem enaka tisti v izhodiščnem tujejezičnem leksemu (ničti pomenski razvoj); 2. v jezik prejemnik se sprejme le eden od pomenov izhodiščnega tujega leksema (pomenska zožitev: zmanjšanje števila pomenov, oženje pomenskega polja oz. področja rabe); 3. prevzeti leksem, lahko tudi neodvisno od izhodiščnega tujejezičnega, pridobiva dodatne nove pomene (pomenska širitev). Takšni pomenski razvoji se radi dogajajo v jezikih, ki so z drugojezično skupnostjo v tesnem, soodvisnem kulturnem, političnem in gospodarskem stiku, ko je privilegirani jezik (nemški) vzor za neprivilegirani jezik (slovenski).

2.1 Primarna pomenska prilagoditev se je izvršila v trenutku sprejema nove besede iz tujejezičnega besedila (prevodne predloge) ali govornega stika v knjižno slovenščino 16. stoletja. Novi pomen sprejete besede je enak tistemu v izhodiščni nemški ali prek nemščine sprejeti latinski besedi, npr. antitrinitar 'pripadnik krščanske sekte, ki ne priznava dogme o sveti Trojici; antitrinitarec', arijan in arijaner 'pristaš nauka meniha Arija iz 4. stoletja, da Kristus po božanstvu ni enak Bogu Očetu; arijanec', cibarij 'kelih s pokrovom za posvečene hostije; ciborij', adiaforist, agenda, antifona 'odpev, predspev', adplicirati 'pridružiti', afekt, agštajn 'jantar', ahat, alkoran, aloe/aloes, ametist, argument, balzam, bazilisk, bdelium 'bdelij', bidertaufar in bidertaufer 'prekrščevalec', celibat, cenzura, cipreš 'cipresa', citrona, damašk 'damast', datelj, definirati, dialektika, disputacija, drahma. Novost in posledično neustaljenost rabe je razvidna tudi iz dvojnih iztočnic, npr. absolucija in absolutio 'odveza', apokalipsa in apocalypsis, beneficija in beneficium, bulenkramer in bulkramar 'prodajalec papeževih listin z odpustki' (nem. der Bullenkrämer), centurio in centurius 'stotnik', cbinglijan in cvinglijaner, decretum in dekret. Na izbiro je vplivala tudi različna prevodna predloga, npr. cimet (der Zimt), cinamet (LB 1545: Cinnamet) in cinamom (lat. cynamomum), dehant (der Dechant) in dekan (der Dekan). V slovarskem sestavku je pomenska razlaga iztočnice, ki jo dopolnjuje sodobna sopomenka in potrjuje konkretna raba, videti takole:

${ }^{5}$ Podrobneje o tem: Filipović 1986: 153-181 in Ajduković 2004b: 191-201; prim. tudi Riehl 2004: 84-86, posebej o tujejezičnem vplivu na besedni red 2004: 86-88. 
alkoran -a sam. m [alko'ra:n -a]; P 8, K $4^{6}$ (JPo 1578, TT 1581-82, TtPre 1588, TPo 1595) /.../ temeljna knjiga muslimanske vere; koran: vekshi del Liudy drugih Potou ifzheio, kuezhnimu Lebnu. Iudye skosi dela nyh Poftau: Turki skosi nyh Alkoran JPo 1578, II, 75; / . . / koku bi ludje mogli od greihov profti inu ledig biti. Htakovimu nuzajo ty Turki fvoj Alcoran, Ty Iudje fvojo Poftavo, Ta Papesh fvoje ordne, Mafhe TPo 1595, III,149, $\mathscr{E}$ iz arab. prek nem., prim. SA 1559 der Alcoran [A. J. $]^{7}$

adiaforist -a sam. m [adiafo'ri:st -a]; P 2, K 1 / .../ pristaš nauka luteranskega teologa Filipa Melanchthona, ki je bil v nebistvenih teoloških vprašanjih blizu katoliškemu nau$k u, v$ vprašanju evharistije pa švicarskim reformatorjem; filipist: Lefemkaj flifhi tudi teh nepokurnih Adiaphoriftou novi Katechifmus, kateriga fo nekoteri v'Wittembergi Anno 1571. slushili .. v'katerim oni v'tem navuki od Vezherje Chriftufove .. sa Sakramentirarji .. teko ZK 1595, 27-28, $\mathscr{E}$ iz gr. prek nem., prim. der Adiaphorist [A. J.]

Iz naštetih zgledov je razvidno, da $\mathrm{v}$ to skupino praviloma sodijo specializirani (enopomenski) leksemi, največkrat iz klasičnih jezikov (povečini sprejeti s posredovanjem nemščine) ali novejši nemški, s katerimi je bila slovenščina v 16. stoletju prvikrat v stiku. Ti so: termini z različnih strokovnih področij, poimenovanja predmetnosti iz eksotičnega kulturnega okolja in daljne preteklosti, ki so bili izkušenjskemu svetu naših prednikov v 16. stoletju neznani (npr. svetopisemsko dogajanje, kulturna krajina), in drugo tematsko besedje. ${ }^{8}$ Razlog za prevzem je bil največkrat poimenovalni primanjkljaj, ki se je pokazal pri prevajanju in prirejanju bibličnih besedil, katekizmov, obrednikov, postil, pesmaric in pri oblikovanju samostojnejših teoloških besedil. Precej tovrstnih zgledov v slovenščini tudi v nadaljnjem jezikovnem razvoju ni doživljalo pomenskih sprememb v smeri širitve oziroma oženja obstoječega pomena, dodatnih pomenov ali premikov v pomenskem polju (npr. prehod specializiranega leksema na drugo tematsko in strokovno področje ali med splošno leksiko).

${ }^{6}$ Krajšava P pomeni število vseh pojavitev iztočnice (z vsemi glasoslovnimi in pisnimi različicami) v korpusu knjižnih del 16 . stoletja, $K$ pa število vseh knjig, v katerih se iztočnica pojavlja (lokacije so v slovarju navedene v oklepaju).

${ }^{7}$ Izbrani odlomki iz slovarskih sestavkov v članku so v delovni fazi pregledov in večstopenjske redakcije, tako da še ne predstavljajo dokončne verzije za objavo v slovarju. Oznaka [A. J.] kot avtorico slovarskih sestavkov alkoran, adiaforist, činž in ceremonija navaja redaktorico Alenko Jelovšek. Za dovoljenje za objavo v prispevku se ji lepo zahvaljujem. Oznaka [A. L. R.] pomeni avtorico tega prispevka.

${ }^{8}$ Tudi najstarejši germanizmi, ki so prišli v slovenščino od 8.-10. stoletja (krščanska terminologija) - največ jih je bilo sprejetih v obdobju od 13. do 15. stoletja - so bili tematsko zamejeni na novejše versko izrazje in besedje s tedaj aktualnih tematskih in strokovnih področij: viteštvo, dvor; vojskovanje; državna uprava in pravo; rokodelstvo in obrt; kmetijstvo in gozdarstvo; kuhinja, jedi in živila; oblačila; igra in zabava; medicina, zdravilne in začimbne rastline (Newerkla 2004: 67-71). 
2.2 Ker se pri prevzemanju $\mathrm{v}$ jezik prejemnik sprejme le eden od pomenov tujejezičnega leksema naenkrat, se v knjižni slovenščini 16. stoletja lahko pojavljajo prevzeti leksemi, ki imajo manjše število pomenov kot izhodiščni leksemi v izvornem (nemškem) jeziku, npr. borcajhen 'kar napoveduje pojavitev česa v prihodnosti; znamenje', cagar 'sončna ura', cajger 'kazalec na sončni uri', cirati 1. 'lepšati, krasiti', 2. 'častiti, slaviti'. Njihova raba v besedilih pretežno verskega značaja ni nujno odraz splošne rabe v 16. stoletju ali v še starejših obdobjih jezikovne zgodovine. Poleg zmanjšanja števila pomenov v odnosu do tujejezičnega leksema se sprememba lahko zgodi tudi v okviru pomenskega polja danega leksema. Prva stopnja sekundarne prilagoditve (adaptacija drugotnih pomenskih sprememb), ki se lahko uresniči že v trenutku prevzema, je zožitev pomenskega polja leksema, ki ima v izhodiščnem jeziku terminološki in splošni pomen, na zgolj neterminološko rabo v knjižni slovenščini 16. stoletja. Na primer prek nemščine sprejeti leksem ara, ${ }^{9}$ znan s strokovnega področja prava (ureja pogodbena razmerja pri izmenjavi dobrin), je v besedilnem korpusu 16. stoletja potrjen le v neterminološkem pomenu: 'kar zagotavlja, jamči za kaj', torej zagotovilo, jamstvo, da se bo uresničilo, kar je obljubljeno. Zaradi skromnih srednjeveških pisnih virov ne moremo dokazovali kontinuite te specializirane rabe v srednjeveški slovenščini, npr. pri trgovanju v kmečkem okolju na sejmih, niti razširjenosti v splošnem pomenu. V 16. stoletju je prepoznan kot splošni leksem, pričakovano v verskih besedilih:

ara -e sam. ž ['a:ra -e]; P 8, K 4 /... / kar zagotavlja, jamči za kaj; zastava: Ta ofma Dobruta nashiga Gofpudi Iefufa Criftufa ie leta, de nom bode fa nega volo dan ta S. Duh, ta je ta nasha Arra, is notra vtim fercej inu vti vifty, ta ifti nas troshta pryzhuye inu faguishuie, de fmo Erbyzhi inu Otroci Boshy TL 1567, 3a; Inu ie nom vtim S. Sacramenti tu fuie Tellu inu tu fuio kry, koker eno Arro oli faftavo inu enu vezhnu fpumnene te nega lubefni pruti nom, dal inu fa febo puftil TC 1575, 452; fte vi tudi fapezhateni, fteim fuetim Duhum od te Oblube, kateri ie ena Arra te nashe Erbfzhine, htimu nashimu odreshituu, de mi bomo ta nega Laltyna, hti huali tiga nega Gofpoftua TT 1581-82, II, 168 / Bug ie pag ta, kir nas fuami red poterduie V criftufu, inu kir ie nas shalbal inu fapezhatil, inu dal to Arro tiga Duha vta nasha ferza TL 1561, 57a, $\mathscr{E}$ iz lat. prek nem., der Ara [A. L. R.]

2.3 Na drugi stopnji sekundarne prilagoditve povsem integrirana prevzeta beseda doživlja nadaljnje pomenske spremembe, največkrat širitev v večpomenskost, ki poteka neodvisno od izhodiščne tuje besede iz prevodnih predlog ali stika s tujejezičnimi govorci. Po osnovnih pomenskih zakonih metaforizacije, metonimizacije in terminologizacije ${ }^{10}$ se v jeziku prejemniku oblikujejo novi pomeni, samostojni

\footnotetext{
${ }^{9}$ Prvi pomen latinske besede arra (arrha $<$ gr. arrabō, arrhabo) je v pogodbah dana zastava, to je 'znesek, ki se plača v potrdilo, da je pogodba sklenjena'; drugi pomen se nanaša na 'zaročno darilo' (Wiesthaler 2007).

${ }^{10}$ Prim. tudi druge postopke širjenja besednega zaklada, ki jih je F. Novak (2004: 73-241) ugotavljal iz knjižnojezikovnega gradiva 16. stoletja. Za obravnavano obdobje so pomembnejši
} 
podpomeni, ki se še navezujejo na določen pomen, in obrobnejši pomenski pojavi - pomenski odtenki, ki jih leksikografi uporabljamo za predstavitev manjših pomenskih sprememb, stalnih besednih zvez, večbesednih lastnoimenskih poimenovanj ipd. ${ }^{11}$ Ko slovarske pomene hierarhično razvrščamo in razlagamo s pomočjo sistemskih pomenskih zakonov, se izkaže, da nekateri zaživijo samostojno, spet drugi se uresničujejo le v določenem sobesedilu; ti besedilni pomeni lahko kasneje postanejo slovarski ali pa izginejo iz rabe. Pri tem je potrebno poudariti, da pri nekaterih prevzetih besedah, ki so v 16. stoletju rabljene v več pomenih, ne gre za novo prevzemanje, temveč za predhoden razvoj že znanih prevzetih besed v večpomenskost (Novak 2001: 107-111, Legan Ravnikar 2013: 132-133). Potrdilo se je, da je najbolj razvita večpomenskost izkazana pri starejših, ustaljenih prevzetih besedah, npr. ajd, ahtati, ajfrati, andlati, andoht, bruma, cagati, cegel, cerati, ceremonija, cerkev, cimper, col, coprati, cviblati, dopasti (vse z razvejanimi besednimi družinami), medtem ko so besede latinskega ali grškega izvora, sprejete prek nove visoke nemščine (15., 16. stoletje) in dostikrat vezane na teologijo, liturgijo, cerkveno upravo in biblijsko stvarnost, eno- ali dvopomenke (gl. 2.1). Na primer prevzeti leksem činž ${ }^{12}$ (srvn. zins) se v knjižnem jeziku 16. stoletja kljub prevladujoči besedilnovrstni zamejenosti na versko področje potrjuje kot pomensko precej razčlenjen, vendar so se drugotni pomeni največkrat oblikovali na podlagi prevodnih predlog. Rabil se je tako neterminološko za poimenovanje vsega, kar je treba dati, prispevati (dajatev, davek, takso, prispevek), kot na različnih tematskih področjih, npr. v okviru fevdalne družbene ureditve, v svetopisemskem okolju, pri opisih o urejanju finančnih pravnih razmerij (dohodki iz različnih naslovov): ${ }^{13}$

še: natančnejše določanje pomenov z opisovanjem (stalne besedne zveze, katerih pomen je razviden iz opisa), približevanje (pri iskanju primernega izraza gre za nepravo izbiro; izbrani izraz je razumljiv, nikakor pa ne običajen v takem pomenu), poosebitev, frazeologizacija, simbolizacija, novi pomeni na podlagi liturgičnih besedil.

${ }^{11}$ Podrobnejše opredelitve stopenj pomenskih enot tudi na podlagi slovarskih praks zadnjih let povzema F. Novak (2004: 69-72): pomen, podpomen, preneseni pomen, pomenski odtenek, stalna besedna zveza. Le-te so lahko: 1. frazemi, 2. strokovni izrazi, 3. drugi večbesedni izrazi, ki so blizu vsoti pomenov teh besed, a so že leksikalizirani.

${ }^{12}$ Slovensko, češko, slovaško činž je prevod nemškega Zins, Tribut, Abgabe, Mitzins (Newerkla 2004: 84, Striedter-Temps 1963: 107). V hrvaški knjižni kajkavščini sta izpričani dve pomenki:1. namet, porez 'davek' (na dediščino, na dohodek), 2. kamate 'obresti', interes (Štebih Golub 2008: 216).

${ }^{13}$ Prim. tudi izhodiščne latinske besede in besedne zveze, ki jih je Kastelec-Vorenčev slovar prevajal z leksemom činž, tudi kot sestavine besednih zvez: anatocismus, zhinsh od zhinșha, velik gréh; census, zhinṡh, dazia; colonarium, zhinșh od nyve /.../ intere/se, obreift, zhinṡh, uher; intere/se â pecunÿs, zhinṡh od danarjou; locare, vdiniati, na zhinsih dati; locatari$u s,-r \ddot{y}$, kateri na zhinṡh vṡame, ali ima; locatio, na zhens்h dajanîe; locator, kateri na zhi[n]sh, ali na fit daje; meritorius, - $a$, -um, tudi na zhinsंh dán; oblocare, v'zhinṡh dati, vdiniati; pensitare, tudi zhinsं[h] plazhovati; reditus, -us, perhodik, zhinsih, naṡai prihod; supercurrere, obilnifhe fadú pernefti, kakòr bi kei en grunt zhinṡha pernellil; tributarius, - $a$, -um, ṡhtiuri, ali zhinṡhu 
činž (činž, činš, činz, cinž) sam. m ['či:nž -a]; P 71, K 16 /.../

Deutfch. Zinß. Latinè. cenfus. Windifch. zhinsh. Italicè. interefse, rendita, entrata MD 1592, H3b; Cenfus. Germa. Schatzung/ die man einen nach feinem angezeigten Gut aufferlegt/ stewr. Sclav. zhinfh. Carniol. zhins MTh 1603, I, $239^{14}$

1. kar se obvezno da, daje v denarju ali naturalijah; davek, dajatev: Nema porozhena od Criftufa, de bi fe ta Duhoufka Oblaft poftauila kanimu Gofpudi zhes vfe Blagu inu zhes vfa Kraleuftua .. De bi ona te Poftaue, Praude od Cinsheu, od Shtyur, od Praud .. hotela rounati inu ftauiti TAr 1562, 91b-92a; /.../

// dajatev, ki jo mora plačevati podrejeno ljudstvo kot znamenje podrejenosti; tribut: /.../ MEsa pak, Moabiterfki Krajl, je imèl veliku Ovaz, inu je Israelfkimu Krajlu zhinfh dajal, volno od ftu taushent Iagnet, inu od ftu taushent Ounou DB 1584, I, 203b; /... /

// v fevdalizmu podložniška dajatev od posestva zemljiškemu gospodu; činž: /.../ Kadar en kmetizh nehozhe brumen, pokoren biti, ni fvojga zhinfha ali praude dati, timu fe nikar krivu ne fgody, kadar njemu njegou Gofpud obuje, njegovu blagu inu pravizo vsame, inu je da enimu drugimu TPo 1595, II, 285

2. dohodek, zlasti od lastnine: Katero ie Pofuetnu Blago? .. Hishe, Duori, Nyue .. Shito, Vino, Slato, Srebro, Dacie, Zhinsh, Dohodak, shpendie JPo 1578, II, 127; / .../

// denarno nadomestilo za začasno uporabo denarja; obresti: /.../ en bogat Vuhernik .. s'fvojemi denarmi velik dobizhek vej fhaffati .. inu bi hotel od ftu rad defset, dvaifseti ali vezh slatih zhinsha imejti TPo 1595, II, 185

3. začasna uporaba česa $v$ zameno za plačilo lastniku; najem: /.../ Deut fch. Vmb zinß hinleihen. Latinè. elocare. Windifch. na zhnish[!] dati. Italicè. dare à pigione, dar affitto MD 1592, S1b

4. plačilo lastniku za začasno uporabo česa; najemnina: /.../ merkaj na eniga, kateriga je ta lokomnoft[:] prou obfejdla .. Aku on naide en prasen kotez vhifhi, taku ftury eno kamrizo is njega, de on en zhinfh od nje vsame TPo 1595 , II, 185, $\mathscr{E}$ iz lat. prek srvn., prim. zins [A. J.]

2.3.1 V zgodovinskem slovaropisju ugotavljamo, da je razkrivanje pomenov leksemov zaradi neinformativnega sobesedila lahko oteženo, posebej kadar je za razumevanje konkretne rabe besede oz. njene pomenske uresničitve nujno poznavanje širšega konteksta ali kar celotnega knjižnega opusa pisca. Pomemben metodološki

podverṡhen, kateri more zhinṡh, inu ṡhtiuro dajati; tributum, -ti, ṡhtivra, zhinṡh, davki, daz; trientariumfoenus, ta zhinṡh, kateri fe vṡame ṡhtiri od ftú; vectigal, zol, zhins்[h], dazia, ṡhtiura, leitni davuk. Pri ugotavljanju pomenske zgradbe leksema v naslednjih desetletjih so bili v pomoč predvsem dvojezični zgodovinski (obrnjeni) slovarji, ki se prav tako nahajajo na spletnem portalu www.fran.si. Prim. tudi Vodnikov obrnjeni slovensko-nemški rokopisni slovar, ki pri iztočnici cinž navaja: Zins, Mietzins, Mietgeld; Cigale (1860) pa der Zins prevaja kot 'davek, najemnina, obresti, najem', medtem ko je leksem činž pod vplivom purističnega jezikovnega nazora manj primerna prevodna ustreznica, označena z zvezdico; tudi pri nemških iztočnicah die Abgabe, der Tribut v slovenskem prevodu činž ni naveden. Nekateri pomeni so se ohranili do prve polovice 19. stoletja; v Pleteršnikovem slovensko-nemškem slovarju (1894-95) pa ta večpomenski leksem ni več izpričan (purizem). Njihove pomene so izražali različni enobesedni izrazi (gl. pripisane sodobne sopomenke v slovarskem sestavku činž).

${ }^{14}$ Neobvezni razdelek »slovarski sklop« predstavlja uvod v razlagalno-ponazarjalni del slovarskega sestavka in je namenjen zgledom, ki jih brez sobesedila in zaradi tujejezičnih večpomenskih ustreznic ni mogoče zanesljivo razvrstiti v ustrezne pomenske enote. 
postopek pri pomenski analizi knjižnega besedja 16. stoletja je tudi primerjava izvirnika in prevoda. ${ }^{15}$ Drugikrat se je potrebno opreti na zunajjezikovne okoliščine, npr. v našem primeru s področij teologije, cerkvene in kulturne zgodovine itd., čeprav so za splošni razlagalni slovar jezikovna dejstva najpomembnejša. ${ }^{16} \mathrm{Na}$ primer glede na aktualno svetovnonazorsko oz. versko usmerjenost slovenskih protestantskih piscev so v besedilnih virih 16. stoletja izpričani starejši prevzeti kot tudi nekateri domači leksemi, ki odražajo protestantski in na nasprotnem polu katoliški odnos do liturgije, teologije in drugih verskih vprašanj. Novi, razločevalni pomeni so se oblikovali z opisom, to je s tvorbo stalnih besednih zvez, npr. prava krščanska cerkov (tudi: prava maša, pravo obhajilo, prava vera ipd.), ki so se v danem trenutku jezikovne zgodovine leksikalizirale. Potrebno jih je razlikovati od prostih besednih zvez, kot so: stara jogrska katoliška rimska cerkov, gmajn prava kristjanska cerkov, prava Kristusova cerkov, prava ino resnična cerkov Kristusova, rimska cerkov : lutrska cerkov. ${ }^{17} \mathrm{Na}$ pomenski razvoj, ki je spodbujen s svetovnonazorskim prepričanjem pisca in dostikrat s tujim prevodnim zgledom, v slovarju opozarjata terminološka kvalifikatorja protest. (jezikovna prvina ali način prikaza, ki zrcali protestantski odnos do obravnavane problematike) in katol. (jezikovna prvina ali način prikaza, ki zrcali katoliški odnos do obravnavane problematike). V odlomku iz slovarskega sestavka cerkev je ta posebnost prikazana v pomenskem odtenku:

cerkev (cerkov, cerkav, cerku, cirkov) sam. ž ['ce:rkev 'ce:rkve]; P približno 3500, K 46 / . ./ 3. ed., pogosto v zvezi s krščanski hierarhično organizirana skupnost pripadnikov krščanske veroizpovedi; krščanska cerkev, Cerkev: ta molh ye glaua te fhene/ koker ye Chriftus tudi glaua te cerque .. koker ye ta Cerkou pokorna Chriftufu/ taku tudi te sakonice fuym molhem bodite pokorne na vfim TC 1550, $136(76 \mathrm{~b}) ; / \ldots /$ / protest. KAI IE

${ }^{15}$ Raziskava A. Erniše (2016) je potrdila, da tovrstna primerjava lahko olajša razumevanje teološkega besedja in da se je Trubar v TPo 1595 tudi na ravni besedja naslanjal na Luthrovo teologijo. Potrdil se je vpliv Luthrove teologije na Trubarjevo teološko izrazje (na primerih terminov božja služba, ceremonija, zakrament, sveti krst in Gospodova večerja). Avtor je analizo dopolnjeval z najtehtnejšimi teološkimi viri in strokovno literaturo. Ugotovil je, da je teološke termine pri Trubarju skoraj nemogoče obravnavati izolirano po posameznih delih, saj je Trubarjev razvoj tako z jezikoslovnega in literarnozgodovinskega kot $s$ teološkega vidika razviden šele iz celotnega opusa, od prvega katekizma (1550) do postile (1595).

${ }^{16}$ Prim. Bibel-lexikon (1968), Biblični leksikon (1984), Splošni religijski leksikon (2007), opombe in razlage v Svetem pismu stare in nove zaveze (1996) ipd.

${ }^{17} \mathrm{Na}$ primer pri osrednjem terminu vera je tovrstnih prilastkovnih zvez dosti in nekatere med njimi izražajo (odvisno od perspektive pišočega) negativno ali pozitivno konotacijo: prava vera, prava krščanska vera, prava izveličanska krščanska vera, prava stara vera, prava stara vera krščanska, stara prava božja vera, prava živa vera, prava živa krščanska vera, evangeliska vera, lutrska vera, jogrska vera, apostolska ali jogrska prava izveličanska vera : kriva vera, kriva nova vera, nova falš vera, kriva hudičeva malikovska vera, faľ̌ vera, falš papeška vera, hudičevalzlodejeva vera, papeževalpapeška vera (Legan Ravnikar 2010: 390). 
TA KERSZHANSKA CERKOV, kei ie, skufi kakoua fnamina fe more ta praua Cerkou fpofnati. TA Kerszhanska Cerkou, na tim fueitu, Ie enu videzhe kardelu inu vkupesbrane vfeh tih ludy kateri ta praui zhifti Nauuk tiga S. Euangelia gori vfamo, primo inu ga slushaio TO 1564, 37a; Potle vftaneio ti napihneni Samohvalniki .. inu bodo fovfo fylo tei pravi Cerkvi, Evangeliu inu pravim Vernim Kàrfzhenikom fe pruti ftavili KPo 1567, XLIIIIb; /.../ / katol. Ne ôte drugako rezhi inu verovati, tàmuzh le nih fama Rimfka fadafhna Cerkov ie ta prava Katholifka kàrfhanfka Cerkov, katere glava bi bil Papefh KPo $1567, \mathrm{CIIb} / \ldots /$

// s prilastkom vsak od delov te hierarhično organizirane skupnosti, ki so nastali v zgodovini:/.../

I protest. TEI PRAVI CERQVI Boshy tiga Slouenskiga Iesika, Miloft inu Myr od Buga ozheta skufi Iefufa Criftufa nafhiga Ohranenica, proflimo TE 1555, A2a; Inu profsite Gofpudi Boga fa me, de on, fa uolo te zhefti inu huale fuiga fuetiga Imena, inu nuza tar goriiemlena te nega boge Slouenske Cerque, meni naprei htakimu teshkimu nuznimu dellu inu piffanu vegsho Gnado inu pomuzh da inu poflodi TT 1557, f3b /.../

// s prilastkom pripadniki te hierarhično organizirane skupnosti; verniki: /.../ Ta ifti ie nemu rekal tim fedmim Cerquom, tu ie, tim kerfzhenikom, kir fo vtih Meiftih vti manshi Afy, vkaterih ie tudi S. Paul inu drugi Iogri pridigali, prebiuali, piffati TtPre 1588, 19; /.../ / protest. tiy fadashnui Papeshi, ti eni Shcoffi, Fary inu Menihi deio, inu vfi ty, kir shnimi dershe, ne fo ta praua Sueta Cerkou Boshya, Temuzh ta huda Caijneshka falsh Cerkou TO 1564, 38a; Per tim prerokuie, de ta praua fueta Kerfzhanska Cerkou, ty Evangelish ludie, bodo mnogetera leita od Papeshnikou inu Turkou terpeli TT 1577, 345; /.../ [A. L. R.]

Tudi to so zgledi pomenskih širitev prevzetih leksemov v danem obdobju knjižnojezikovne zgodovine.

\section{Spremembe v pomenski zgradbi domačih leksemov zaradi sprejemanja novih pomenov}

Nemške prevodne predloge protestantskih verskih besedil so vplivale tudi na pomenske spremembe domačih besed, rabljenih $\mathrm{v}$ prevedenih in prirejenih besedilih 16. stoletja. Pri t. i. semantičnem prevzemu prevod tujejezičnega leksema z že obstoječo domačo besedo privede do njenega pomenskega razvoja v smer večpomenskosti. Ustaljeni domači leksemi so pridobivali nove pomene, katerih nosilci so bili v jeziku dajalcu različni tujejezični leksemi, npr. beseda, bogat, bolezen, čast, čist, čuti, dober, dolg sam. in prid. ki so oblikovali razvejane besedne družine. Semantični razvoj domačih leksemov je bil prav tako razlog za manjše število knjižnih besed 16. stoletja, ki pa so bile pomensko tako bogato razčlenjene, da so slovenski protestantski pisci lahko suvereno ubesedili zapleteno vsebino celotnega Svetega pisma, ene najbolj monumentalnih knjig svetovne kulturne dediščine. 
3.1 Poglejmo si zgled splošno razširjenega pridevnika skupnega slovanskega izvora čuden..$^{18} \mathrm{~V} 16$. stoletju so se s pridevnikom čuden prevajali nemški izrazi: wunderbar/wunderbarlich 'čudovit, čudežen', wunderlich 'čuden, čudaški', unnatürlich 'nenaraven', ungewohnt 'neobičajen', gar wundersam 'prečudovit', seltsam 'čuden, nenavaden', abscheulich 'ki ima negativne lastnosti v moralnem pogledu'. Večpomenka čuden torej v knjižni slovenščini 16. stoletja izkazuje zapleteno pomensko zgradbo in jo v sodobnem jeziku nadomeščamo z naslednjimi sopomenkami (v pomenskih razlagah za podpičjem):

čuden ${ }^{2}$ (čuden, čudan, čudin) -na -o prid. ['ču:den -na -o]; P približno 450, K 36 / .../

Deutfch. Wunderbarlich. Latinè. admirabilis. Windifch. zhudèn. Italicè. maravigliofo, mirabile, cofa degna d'ammiratione, oltre ad ogni credenza MD 1592, V7a; Prodigiofus. Germ. vnnatürlich/gar wunderfam/ das fich wider der Natur Lauff zutregt. Sclav. zhuden MTh 1603, II, 331; Rarus. Germ. dünn/ lück. Sclav. Zhuden MTh 1603, II, 394-395

1. ki se zelo razlikuje od navadnega, znanega; čuden, nenavaden: /.../ taku fe vejtri obrazhajo, inu Snejg okuli vihrajo, de na kup pada, kakòr kobilize doli fedajo. On je taku bèl, de ozhy flipy, inu ferze fe mora sazhuditi takoviga zhudniga deshja DB 1584, II, 171a (prim. nem. solchs seltsams Regens, LB 1545, 1815) /.../

// ekspr. ki se po nečem posebej razlikuje, loči od drugih; čudaški: /.../ TV nashe obhaylu inu Mashouane, kir pres tiga mashniga guanta inu zhaßi pres koratla .. Altarie kushouane, inu zhudniga, norlkiga ispazheniga kauklane .. vfem pokurnim inu Vernim dilimo inu iemlemo TC $1575,169-170 / \ldots /$

2. ver. ki se ne da razložiti z naravnimi zakoni; čudežen: Potle k'drusimu, kako ti hinavci Chriftufova zhudna dela alli zaihne rihtueio, opravläio, inu dershè, sa eno Hudizhovo delo KPo 1567, CXIX; /.../

3. ki zaradi pozitivnih značilnosti vzbuja oz. je vreden občudovanja; čudovit: /.../ Po katerim [po Rdečem morju] je thal vus folk, kateri je pod tvojo roko bil obarovan, kateri fo takove zhudne zajhne vidili .. inu fo tebe hvalili DB 1584, II, 146b (prim. nem. Wünderlich Wunder, LB 1545, 1729) /.../

4. ki vzbuja velik strah, grozo; grozen, grozovit: /.../ Inu vus Folk mej katerim fi ti, ima viditi, tu Dellu tiga GOSPVDA: Sakaj tu bode *ftrafhnu, kar jeft bom s'tabo fturil <*ali zhudnu> DB 1584, I, 58a (prim. nem. wunderbarlich, LB 1545, 188) /.../

// ki prinaša veliko trpljenja, mnogo težav: Glih taku fhe fdai/ fuio Cerkou te kerfzhenike Itrafa/ Imogetero[!] rizho koker Sturki/ fdragino/ fhlifami/ fzhudnimi bolefanmi/ Thudo gofpolzhino TC 1550, 219 (117b) /.../

5. ki ima, kaže v odnosu do ljudi negativne lastnosti, zlasti v moralnem pogledu; hudoben: Vy Hlapci inu Slufhabniki/ bodite pokorni vafhim telefnim gofpudom .. nakar le tim dobrim inu mehkim/ temuzh tudi tim zhudnim TC 1550, 140 (78b) / taku jeft tebe profsim vfigamogozhi Bug, de ti vfeh Tyrannou inu nedobrutliuih Gofpudou miffal, inu zhudnu inu nemiloftiuu ferce .. skusi tuoio miloft, hozhesh miloftiuu obernyti TkM 1579, 24a brezsrčnost, nesočutnost; /.../ [A. L. R.]

${ }^{18}$ Pridevnik čuden se pojavlja tudi v samostalniški funkciji: kdor ima nenavadne, izredne lastnosti, sposobnosti; čudežni: kot vzdevek ta Prerok [Izaija] GOSPVDV Chriftufu fheft imena da, ga imenuie zhuden, Svit, Krafft, Iunak, Vezhni Ozha inu Myrni Vyuda TPo 1595, I, 73 [A. L. R.]. 


\section{Vpliv nemškega jezika na stilno vrednost prevzetih in domačih leksemov}

Pri obravnavi vpliva tujejezične leksike na (ne)zaznamovanost prevzetih in domačih leksemov imamo v mislih vsak stilem v besedju jezika prejemnika, ki je nastal pod dominantnim vplivom jezika dajalca (Ajduković 2004b: 225). Znano je, da slovarski pomenski opis dopolnjujejo neslovnični kvalifikatorji, ki natančneje opredeljujejo različne vrste konotativnosti, ${ }^{19}$ in kvalifikatorska pojasnila, od katerih nekatera opozarjajo na zunajjezikovne okoliščine rabe (pragmatični pomen). Med kvalifikatorje, ki vrednotijo jezikovna sredstva $\mathrm{v}$ razmerju do drugih jezikovnih sredstev, spadajo tudi ekspresivni ali čustvenostni kvalifikatorji. Kvalifikator ekspr. v nastajajočem Slovarju slovenskega knjižnega jezika 16. stoletja označuje čustveno razmerje do poimenovanega $\mathrm{v}$ najširšem pomenskem obsegu, ker ga je zaradi pomanjkljivih informacij - ki so posledica velike časovne odmaknjenosti in odsotnosti jezikovnega občutka redaktorja za tedanjo jezikovno situacijo - težko natančno in nedvoumno opredeliti. ${ }^{20}$ Ekspresivna leksika prinaša: 1. podatek o zaznamovanosti leksema, ki je pogojen z objektivno ali subjektivno oceno govorcev (označujemo s kvalifikatorjem ekspr.), 2. informacijo, kakšen odziv želimo doseči pri naslovniku z njeno izbiro (v našem slovarju se izraža s kvalifikatorjema iron. in slabš., ki jima je skupen negativni odnos do poimenovanega) in 3. sporočilo o primernosti uporabe določenega leksema glede na udeležence in okoliščine sporazumevanja (v našem slovarju zajeto s kvalifikatorjema vznes. in evfem.). ${ }^{21}$

${ }^{19}$ A. Vidovič Muha (po J. Zimi, Eksprisivita slova v současné češtině, 1961) govori o dveh tipih konotativnosti (2013: 109-112): o prvotni ali inherentni, ki izhaja iz oblike leksema in je vgrajena $\mathrm{v}$ formo oz. morfematiko leksema (npr. različni tipi tvorjenk, nenavadne glasovne strukture pri netvorjenkah), vključujoč tudi nadsegmentne lastnosti, in drugotni ali adherentni konotativnosti, ki nastane $\mathrm{v}$ enem ali več neprvih pomenih večpomenskega leksema.

${ }^{20}$ Glede na stanje v slovaropisni tradiciji sodobnega knjižnega jezika A. Žele (1993: 530) poudarja, da ima oznaka ekspr. širši pomen. Označuje splošno poznan odnos do stvari, splošno veljavno oceno, izhajajočo iz lastnosti oz. vsebine poimenovane predmetnosti, ki se izrazi na različne načine, in šele na drugem mestu je odnos do te predmetnosti oz. z njim povezana zaznamovana raba določenega poimenovanja. Hierarhično podrejeni ekspresivni kvalifikatorji so tudi v slovarju knjižnega jezika 16. stoletja tradicionalno opredeljeni: slabš. je oznaka za jezikovno prvino, ki izraža podcenjevalen ali zaničljiv odnos do poimenovanega; evfem. je poimenovanje, s katerim se pisec skuša izogniti neprijetnemu, neprimernemu izrazu; iron. izraža prikrit posmeh in ima pogosto nasproten pomen od izhodiščnega; vznes. izpostavlja jezikovno prvino, ki izraža spoštljivo, slovesno razmerje do poimenovanega. Poleg ekspresivnih se med neslovnične kvalifikatorje v zgodovinski slovar uvrščajo tudi pomenski kvalifikatorji, terminološki, socialnozvrstna kvalifikatorja, pogostnostni, gotovostni kvalifikator (negotovo) in stilni kvalifikator (pleon.) (Merše itd. 2001: 23-25), Priročnik za sestavljanje in vpisovanje gesel, Različica 2016, 48-49 (interno gradivo).

${ }^{21}$ Deloma povzeto po Stramljič Breznik (2013: 414-415). Ekspresivna leksika torej deluje na presečišču treh dimenzij jezika: pomen (semantika), raba (pregmatika) in izbirnost jezikovnih sredstev (stilistika). 
4.1 V versko razgibanem času 16. stoletja je bil odnos pripadnikov različnih protestantskih cerkva do katolikov (in obratno) zelo odklonilen in celo zaničevalen. $\mathrm{Na}$ tem mestu je zaznati neposreden vpliv nemških prevodnih predlog, ki so narekovale pomenske premike v smer pejorativnosti. Tovrstne spremembe so doživljali stari prevzeti krščanski termini, npr. ceremonija, menih, nuna, papež, odpustek ipd., manjkrat so bili zaznamovani tudi domači leksemi, npr. dobrovoljen:

ceremonija (ceremonija, ceromonija) -e sam. ž [cere‘mo:nija -e]; P 117, K 18 /.../

1. javno versko dejanje ali dogajanje, navadno s simbolnim pomenom, katerega potek je ustaljen, predpisan; verski obred: Vkakoui vishi, koku, fzhim inu per zhem, skakouo Ceremonio, ie Iefus to fuio Vezherio (katera fe fdai Maflha imenuie) imel, dershal, peil inu obhaial TC 1555, K1b; /... / slabš. Boshijo befedo poflufhati .. ie ta vezhni leban. Zhlovelki ûk pak, inu Ceremonie tèr poftave fo ena kriva fpazhena niftar vredna Boshija flushba KPo 1567, CXXXV; /.../ Koku je tudi na leti ftrani pèr nas, inu mej Papefhtvom .. ta zhifta prava Boshja Beßeda ferrahtana, pruti tem vunanim Papefhkim Ceremonia[!], navadam, pranganjem inu drugim zhlovezhkim sapuvidam inu naredbam DB 1584, $\mathrm{II},+\mathrm{IIb} / \ldots /, \mathscr{E}$ iz lat., prim. caeremonia [A. J.]

dobrovoljen (dobrovolen, dobrovoljan, dobrovoln) -ljna -o prid. [dobro'vo:ljen -ljna -o]; P 21, K 4 /...

1. ki temelji na svobodni volji, odločitvi; prostovoljen: /.../2. navadno v povedni rabi ki ima voljo, pripravljenost za kaj; voljen: /.../3. ki ima razumevajoč, strpen odnos do koga; prizanesljiv: Ozha odpufti nym sakai oni nesnaio kai delaio. Ako pak nebudesh proshen, tako vfai dobro volian budi kodpufzhaniu JPo 1578, II, 117b; / iron. Kpervimu on nyh imenuie flipazhke Voinike, kateri fami febe inu drugih, skosi fuoie dobrouolno obfoienie sapeliuio: Ieli mogozhe dabi Slipaz flepzu pot kasal JPo 1578, II, 106b [A. L. R.]

4.2 Ob soočenju ekspresivnosti s stališča inherentnosti, ki je vidna v izrazni podobi, $\mathrm{z}$ adherentno ekspresivnostjo, ki je pridobljena npr. z zamenjavami pomenov (metonimija, sinekdoha) in prepoznana iz rabe v sobesedilu, opažamo, da se druga v 16. stoletju pojavlja precej pogosteje. Na primer tvorbeno razvidne manjšalnice (priponska obrazila $\mathrm{z}$ besedotvornim pomenom manjšalnosti, majhnosti), nastale z modifikacijsko izpeljavo, so bile večkrat spodbujene s tujejezično predlogo, vendar vpliv nemščine ni bil tolikšen, kot bi morda pričakovali. Na omejenem številu zgledov v geselskih člankih (od A do vključno D) se je izkazalo, da se pomenska razlaga nujno ne ujema z besedotvorno, zato se tovrstnih slovarskih razlag pri redakciji izogibamo, npr. banderce 'zastava, prapor' (prim. nem. Fenlin, LB 1545, 1219), culce 'mošnjiček za denar' (prim. nem. Bundlin, LB 1545, 932, ein bundelein/ bufchelein, MTh 1603), cafelc 'želodu podoben predmet, ki se kam zatakne' (prim. nem. Zapflin, MTh 1603). Izpričani so tudi zgledi, ko priponsko obrazilo za manjšalnost ni spodbujeno s prevodno predlogo, npr. ahkerec 'izzidek, pomol' (prim. nem. Ercker, LB 1545, 1089), človeče (prim. nem. mensch, LH 1566, III, LXIIIIb), časek 'hip, trenutek' (beseda v prevodni predlogi ni izpričana). ${ }^{22}$

${ }^{22}$ Na podlagi primerjave obrazilno raznolikih samostalniških manjšalnic je M. Merše tako $\mathrm{v}$ svetopisemskih prevodih kot postilah ugotovila visoko stopnjo skladnosti, ob njej pa tudi 
Slovarski pomeni iztočnice besedica na primer razkrivajo na podlagi metonimije, sinekdohe in metafore izvršene pomenske prenose iz kategorije majhnosti na: kratkost ('najkrajša beseda, ki nekaj pomeni'), zamenjavo del - celota, (kratka misel kot del večjega sporočila), 'zadnji del celote' (slednja besedica), s pomenskim prenosom v 'kar je malo pomembno, malo vredno' (tedaj frazeološko zaznamovana enota ena sama besedica) ali 'prav ničesar' (frazem z glagoli rekanja v zanikani obliki: ene besedice); najširši pomenski obseg ima besedica v 3. pomenu: 'obljuba, zagotovilo'. Izbira besede, tvorjene z modifikacijsko izpeljavo, izraža dodatne konotacije, na katere smo opozorili s splošnejšim kvalifikatorjem ekspr.:

besedica (besedica, besejdica) -e sam. ž [be'se:dica -e]; P 60, K 8 /.../

1. ekspr. posamezna jezikovna enota iz glasov ali črk $v$ govoru ali pisanju, ki nekaj pomeni; besedica: /.../ inu my sanikerni ludje, kakor hitru eden nas le eno Latinfko, Gerlko ali Ebreifko befsédizo sna inu vmej, taku od offerti ne vejmo, kej bi my imejli oftati TPo 1595, III, 133 (prim. nem. vocabel, LH 1566) /.../

- - zanikano, z glagoli rekanja ene besedice prav ničesar; ene besedice: Ieli to ta priasliv Mosh, od kateriga fo meni tulikai pravili, inu ga hvalili? Tèr mi nezhe ene befedice vofchiti? KPo 1567, CXV; /.../

- - Sakaj onu fe hitru pergody, de ti fa volo ene fame befsedeze, katera tebi kej nej dopadla, od ferda bolh premagan TPo 1595, II, 161 malenkosti

2. ekspr. kratka misel, izražena z besedami: Inu k'meni je prifhla ena fkriuna befleda, inu moje uhu je eno beffedizo is teifte prejela[!] DB 1584, I, 267a (prim. nem. wörtlin, LB $1545,921)$

3. ekspr. izjava, da bo kdo česa deležen ali da se bo zagotovo kaj uresničilo; obljuba, zagotovilo: Ne bui fe Maria, ti fi gnado per Bugi nafhla. Leto befsédizo ti dobru merkaj, Sakaj ona nej le htimu flushila, de bi ta Dekliza s'hnjo potrolhtana bila, temuzh de bi timu grofovitimu Malikovainju brainenu bilu, kateru fe je potle mej temi Karfzheniki, Ikusi tiga Papelha inu Menihe snafhlu TPo 1595, III, 64 (prim. nem. wörtlein, LH 1566) / .../ [A. L. R.]

Ker konotativni pomeni v največji meri odražajo avtorjev ali prevajalčev osebni odnos do tematike, smo predvidevali, da je v primerjavi s prej omenjenimi možnostmi prav vpliv prevodnih predlog na stilno vrednost knjižnih besed 16. stoletja najmanj izrazit oz. najmanjši. To nam vsaj shematično dokazujejo navedeni zgledi pomensko neodvisne rabe besed tujega in domačega izvora, ki smo jih predstavili.

nekaj neodvisnih rab manjšalnic, ki dokazujejo zavestno izbiro za stilno učinkovito izrabo (2010: 52, 59-60). Pri tem dodajamo, da ni nujno, da so se nove manjšalnice s ponovnim dodatkom obrazila -ica izpeljevale, ker se je pri prvostopenjskih manjšalnicah izgubil manjšalni pomen. Redakcija gesla deklica je pokazala, da poleg znanega osnovnega pomena 'oseba ženskega spola do pubertete' v 16. stoletju pomeni tudi 'dekle', 'devica' in 'dekla', drugostopenjsko tvorjenko dekličica pa navaja le Bohorič, in sicer kot vzorčno besedo pri spoznavanju slovnice. Tudi devičica (Jungfrau) je v vseh 23 zgledih, ki se pojavljajo izključno v TPo 1595, potrjena samo kot poimenovanje za Jezusovo mater Marijo in je zaradi konotativne rabe opremljena s kvalifikatorjem vznes. 


\section{Sklep}

Jezikoslovna analiza vzorca prevzetih in domačih knjižnih besed 16. stoletja z začetnicami od A do vključno $\mathrm{D}$, pri katerih smo ugotavljali vpliv nemščine na njihove semantične spremembe, dopušča omejeno reprezentativnost. $V$ tem okviru se je potrdilo, da je bil pod vplivom prevodnih predlog semantični razvoj v večpomenskost tako pri prevzetih kot domačih leksemih splošen pojav. Predstavlja enega od razlogov za številčno skromen obseg knjižne leksike 16. stoletja (nekaj nad 22.000 besed), ob upoštevanju dejstva, da je bila količina uporabljenega besedja odvisna od funkcionalnih potreb knjižnega jezika v 16. stoletju, ki niso primerljive $z$ današnjim časom. Najstarejši knjižni leksemi so bili namreč pomensko precej bolj obremenjeni, kot to velja za primerljivo besedišče sodobnega knjižnega oz. standardnega jezika. Razlog za pomenske razvoje $\mathrm{v}$ večpomenskost pripisujemo tudi praktičnim stališčem in ravnanju protestantskih piscev, ki so pri poimenovalnem primanjkljaju predvsem ustaljenim prevzetim in domačim leksemom dodajali nove pomene, kar je bilo lažje in hitreje, kot če bi tvorili nove besede, in primerneje, kot če bi kalkirali ali nekritično prevzemali iz tujih jezikov. Raba večpomenskostnih poimenovalnih postopkov je bila ne glede na tujejezično spodbudo odraz ubesedovalne ustvarjalnosti slovenskih protestantskih piscev in izrazne moči slovenskega jezika v 16. stoletju.

\section{Viri}

Cigale 1860 = Cigale, Matej, Deutfch-flovenifches Wörterbuch, Laibach: Gedruckt bei Iosef Blasnik, 1860.

DB 1584 = Dalmatin, Jurij, BIBLIA, Wittenberg, 1584 .

FDW 1989-=Frühneuhochdeutsches Wörterbuch, Berlin, New York: Walter de Gruyter, 1989-.

Grimm 2004 = Der digitale Grimm. Deutsches Wörterbuch von Jakob und Wilhelm Grimm, Version 05-04, Frankfurt am Main: zweitausendeins, 2004.

JPo 1578 = Juričič, Jurij, POSTILLA, Ljubljana, 1578.

KB $1566=$ Krelj, Sebastijan, OTROZHIA BIBLIA, Regensburg, 1566.

KPo 1567 = Krelj, Sebastijan, POSTILLA SLOVENSKA, Regensburg, 1567.

LB 1545 (1974) = Luther, Martin, Biblia, Das ist: Die gantze Heilige Schrifft Deudsch auffs new zugericht, Wittenberg, 1545, München, 1974.

LH 1566 = Luther, Martin, Haußpoftill I-III, Nürnberg, 1566.

MD 1592 = Megiser, Hieronymus, DICTIONARIVM QVATVOR LINGVARVM, Graz, 1592.

MTh 1603 = Megiser, Hieronymus, Thefaurus Polyglottus, Frankfurt, 1603.

PS 2001 = Merše, Majda - Novak, France - Premk, Francka, Slovar jezika slovenskih protestantskih piscev 16. stoletja: Poskusni snopič, Ljubljana: Založba ZRC, ZRC SAZU, 2001.

SA 1559 = Spangenberg, Johannes, Außflegungen der Episteln vnd Euangelien, Nürnberg, 1559.

TAr 1562 = Trubar, Primož, ARTICVLI OLI DEILI, TE PRAVE STARE VERE KERSZHANSKE, Tübingen, 1562.

TC 1550 = Trubar, Primož, Catechifmus, Tübingen, 1550 . 
TC 1555 = Trubar, Primož, CATECHISMVS, Tübingen, 1555.

TC 1575 = Trubar, Primož, CATEHISMVS SDVEIMA ISLAGAMA, Tübingen, 1575.

TE 1555 = Trubar, Primož, TA EVANGELI SVETIGA MATEVSHA, Tübingen, 1555

TfC 1595 = Trubar, Felicijan, TA CELI CATEHISMVS, ENI PSALMI, Tübingen, 1595.

TkM 1579 = Tulščak, Janž, Kerjzhanske LEIPE MOLITVE, Ljubljana, 1579.

TL 1561 = Trubar, Primož, SVETIGA PAVLA TA DVA LISTY, Tübingen, 1561.

TL 1567 = Trubar, Primož, SVETIGA PAVLA LYSTVVI, Tübingen, 1567.

TO 1564 = Trubar, Primož, CERKOVNA ORDNINGA, Tübingen, 1564 .

TPo 1595 = Trubar, Primož, HISHNA POSTILLA, Tübingen, 1595.

TT 1557 = Trubar, Primož, TA PERVI DEIL TIGA NOVIGA TESTAMENTA, Tübingen, 1557.

TT 1577 = Trubar, Primož, NOVIGA TESTAMENTA PVSLEDNI DEIL, Tübingen, 1577.

TT 1581-82 = Trubar, Primož, TA CELI NOVI TESTAMENT, Tübingen, 1581-82.

TtPre 1588 = Trošt, Matija, ENA LEPA INV PRIDNA PREDIGA, Tübingen, 1588.

Wiesthaler 1993-2007 = Latinsko-slovenski slovar 1-6. Ljubljana, 1993-2007.

www.fran.si

ZK 1595 = Znojilšek, Janž, KATECHISMVS DOCTORIA MARtina Luthra, Tübingen, 1595.

\section{Literatura}

Ајдукровић, Јобан. 2004а. Контактолошки речник адаптаичје русизама: у осам словенских језика/ Контактологический словарь адаптации русизмов: в восьми славянских языках. Београд: Фото Футура.

Ајдукровић, Јоbан. 2004b. Увод у лексичку контактологију. Теорија адаптације русизама. Београд: Фото Футура.

Bibel-lexikon. 1968. Zweite, neu bearbeitete und vermehrte Auflage. Tübingen: Benziger Verlag.

Erniša, Aleksander. 2016. Primerjava prevoda in izvirnika kot model za določanje pomena teološkega besedja $v$ delih slovenskih protestantskih piscev 16. stoletja na primeru Trubarjevega prevoda Luthrove Hišne postile. Doktorska disertacija [rokopis]. Ljubljana: Podiplomska šola ZRC SAZU.

Filipović, Rudolf. 1986. Teorija jezika u kontaktu: uvod u lingvistiku jezičnih dodira. Zagreb: Školska knjiga.

Grabner Haider, Anton - Kraševec, Jože s sodelavci. 1984. Biblični leksikon. Celje: Mohorjeva družba.

Hock, Hans Henrich. 1991 ${ }^{2}$. Principles of Historical Linguistics. Second revised and updated edition. Berlin, New York: Mouton de Gruyter.

Legan Ravnikar, Andreja. 2010. Terminološki in stilistični vidik poimenovanja verskih pojmov $\mathrm{v}$ protestantizmu in obdobju katoliške prenove. Reformacija na Slovenskem: ob 500-letnici Trubarjevega rojstva, 385-399. (Obdobja 27.) Ljubljana: Znanstvena založba Filozofske fakultete.

Legan Ravnikar, Andreja. 2012. Značilnosti sprejemanja besed iz nemščine v knjižno slovenščino 16. stoletja. Jezikoslovni zapiski 18/2, 131-148.

Legan Ravnikar, Andreja. 2013. Prevzete besede neslovanskega in slovanskega izvora v knjižni slovenščini 16. stoletja. Slovensko in slovansko, (Jezikoslovni zapiski 19/1), 129-142. Ljubljana: Inštitut za slovenski jezik Frana Ramovša ZRC SAZU.

Legan Ravnikar, Andreja. 2014. Problematika germanizmov v zgodovinskem slovarju knjižne slovenščine 16. stoletja. Slovenski jezik na stičišču več kultur, 70-84. Maribor: Zora. 
Merše, Majda. 2010. Raba samostalniških manjšalnic v delih slovenskih protestantskih piscev 16. stoletja. Slavistična revija 58/1, 45-63.

Newerkla, Stefan Michael. 2004. Sprachkontakte Deutsch - Tschechisch-Slowakisch. Worterbuch der deutschen Lehnwörter im Tschechischen und Slowakischen: historische Entwicklung, Beleglage, bisherige und neue Deutungen. Frankfurt am Main: Peter Lang, Europäischer Verlag der Wissenschaften.

Novak, France. 2001. Kako so protestantski pisci poimenovali nove pojme. 450-letnica slovenske knjige in slovenski protestantizem, 103-120. Ljubljana: Slovensko protestantsko društvo Primož Trubar, Znanstveni inštitut Filozofske fakultete.

Novak, France. 2004. Samostalniška večpomenskost v jeziku slovenskih protestantskih piscev 16. stoletja. Ljubljana: Založba ZRC, ZRC SAZU.

Reindl, Donald F. 2008. Language Contact: German and Slovenian. Bochum: Universität Dr. N. Brockmeyer.

Riehl, Claudia Maria. 2004. Sprachkontaktforschung: eine Einführung. Tübingen: Gunter Narr Verlag.

Splošni religijski leksikon. 2007. Bajt, Drago in Kocjan-Barle, Marta (urednika slovenske izdaje). Ljubljana: Modrijan.

Stramljič Breznik, Irena. 2013. Samostalniška leksika z ekspresivnimi kvalifikatorji v slovarju novejšega besedja. Družbena funkcijskost jezika: vidiki, merila, opredelitve, 409-416. (Obdobja 32.) Ljubljana: Znanstvena založba Filozofske fakultete.

Striedter-Temps, Hildegard. 1963. Deutsche Lehnwörter im Slowenischen. Wien: Im Kommision bei Otto Harrasowitz.

Sveto pismo stare in nove zaveze. 1996. Slovenski standardni prevod iz izvirnih jezikov. Ljubljana: Svetopisemska družba Slovenije.

Štebih Golub, Barbara. 2010. Germanizmi kajkavskoga književnog jezika. Zagreb: Institut za hrvatski jezik i jezikoslovlje.

Vidovič Muha, Ada. 2013. Slovensko leksikalno pomenoslovje. 2., dopolnjena izdaja. Ljubljana: Znanstvena založba Filozofske fakultete.

Žele, Andreja. 1993. Ekspresivne oz. čustvenostne oznake v slovarstvu. Slavistična revija 41/4, $529-534$.

Prispelo marca 2017, sprejeto maja 2017.

Received March 2017, accepted May 2017. 


\section{K problematiki vpliva stičnega jezika - nemščine na semantične spremembe in stilno vrednost najstarejše slovenske knjižne leksike (16. stoletje)}

S pomočjo teoretičnih izhodišč in raziskovalnih metod kontaktnega jezikoslovja želimo ugotoviti, katere pomenske spremembe so doživljali prevzeti leksemi v primerjavi z izhodiščnimi nemškimi (ali latinskimi, sprejetimi s posredovanjem nemščine) $v$ procesu integracije $v$ slovenski jezikovni sistem in knjižni jezik 16. stoletja. Rezultat jezikovnega stika na semantični ravni je adaptacija pomena tuje besede (t. i. modela) iz jezika dajalca $\mathrm{v}$ sprejeto besedo (t. i. repliko) $\mathrm{v}$ jeziku prejemniku. Pokazale so se tri možnosti prenosa pomena. (1) Novi pomen prevzete besede $\mathrm{v}$ jeziku prejemniku je povsem enak tistemu $\mathrm{v}$ izhodiščnem tujejezičnem leksemu (to je ničti pomenski razvoj), npr. antitrinitar, alkoran, aloelaloes, cenzura, de$k a n$, disputacija. Iz izbranih zgledov je razvidno, da $\mathrm{v}$ to skupino praviloma sodijo specializirani leksemi, največkrat iz klasičnih jezikov ali iz nove visoke nemščine, $\mathrm{s}$ katerimi je bila slovenščina $\mathrm{v} 16$. stoletju prvikrat $\mathrm{v}$ stiku. (2) $\mathrm{V}$ jezik prejemnik se sprejme le eden od pomenov izhodiščnega tujejezičnega leksema (pomensko oženje). Prva stopnja sekundarne prilagoditve (adaptacija drugotnih pomenskih sprememb) se lahko izvrši že v trenutku prevzema. Gre za oženje pomenskega polja (področja) leksema, ki ima v izhodiščnem jeziku specializirani (največkrat terminološki) pomen in (po determinologizaciji) splošni pomen, na zgolj splošno rabo v knjižni slovenščini 16. stoletja, npr. ara 'kar zagotavlja, jamči za kaj'. (3) $\mathrm{Na}$ drugi stopnji sekundarne prilagoditve prevzeti leksem pridobiva nove, dodatne pomene (pomenska širitev), tudi neodvisno od izhodiščnega tujega, npr. činž. Tudi prevod tujejezičnega leksema $\mathrm{z}$ že obstoječo domačo besedo lahko privede do njenega pomenskega razvoja $\mathrm{v}$ večpomenskost, kar vsekakor dokazuje upovedovalno ustvarjalnost slovenskih protestantov in izrazno moč slovenskega jezika. Na primer s pridevnikom čuden so se prevajali nemški leksemi: wunderbarlich, wunderlich, unnatürlich, ungewohnt, gar wundersam, seltsam, abscheulich, zaradi česar ima ta pridevnik v knjižni slovenščini 16. stoletja kar pet pomenov in dva podpomena. Pod dominantnim vplivom jezika dajalca iz prevodnih predlog so nekateri leksemi ob slovarskem pomenu pridobili dodatne konotativne pomene. Pri analizi smo se omejili na rabo, ki jo v nastajajočem Slovarju slovenskega knjižnega jezika 16. stoletja označujejo ekspresivni kvalifikatorji: ekspr., slabš., iron., evfem., vznes. Pogosto je šla konotativnost v smer pejorativnosti, ki so jo doživljali predvsem stari prevzeti krščanski termini, npr. ceremonija, menih, nuna, papež, odpustek ipd. Tudi tvorbeno razvidne manjšalnice so bile večkrat spodbujene s tujejezično predlogo, vendar vpliv nemščine ni bil tolikšen, kot bi morda pričakovali. Na omejenem številu analiziranih zgledov (od A do vključno D) se je izkazalo, da se pomenska razlaga nujno ne ujema z besedotvorno, npr. banderce 'zastava, prapor' (prim. nem. Fenlin, 
LB 1545, 1219), cafelc 'želodu podoben predmet, ki se kam zatakne' (nem. Zapflin, MTh 1603), po drugi strani tudi priponsko obrazilo za manjšalnost ni bilo vedno spodbujeno s prevodno predlogo, npr. ahkerec 'izzidek, pomol' (nem. Ercker, LB 1545, 1089), človeče (nem. mensch, LH 1566, III, LXIIIIb).

Jezikoslovna analiza je potrdila, da je semantični razvoj v večpomenskost tako pri prevzetih kot domačih leksemih eden od pomembnih razlogov za številčno skromen obseg knjižne leksike 16. stoletja (nekaj nad 22.000 besed). To je poleg funkcijskozvrstne zamejenosti knjižne leksike mogoče pripisati tudi praktičnim stališčem in ravnanju protestantskih piscev, ki so pri poimenovalnem primanjkljaju ustaljenim prevzetim in domačim leksemom dodajali nove pomene, kar je bilo lažje in hitreje, kot če bi tvorili nove besede, kalkirali ali pretirano prevzemali iz tujih jezikov. Raba večpomenskostnih poimenovalnih postopkov pa je bila ne glede na tujejezično spodbudo tudi odraz ubesedovalne ustvarjalnosti slovenskih protestantskih piscev in izrazne moči slovenskega jezika v 16. stoletju.

\section{Issues regarding the influence of a contact language: German influence on semantic change and stylistic values of the oldest Slovenian literary lexica (16th century)}

We aim to investigate (by way of theoretical principles and research methods of contact linguistics) semantic change affecting loanwords in comparison to the original German (or Latin, mediated through German) lexemes during the process of integrating into the Slovenian language system and the 16th century literary language. The result of language contact was the adoption of the meaning of a foreign word from the donor language (the so-called 'model') by the loanword in the borrowing language (the so-called 'replica'). Three possible meaning transfers have been noted. (1) The new meaning of the loanword in the borrowing language is the same as that of the original foreign lexeme (i.e. zero-development of meaning), e.g. antitrinitar (antitrinitarian), alkoran (alcoran), aloelaloes, cenzura (censorship), dekan (dean), disputacija (disputation). The selected examples show that this group normally contains specialized lexemes, most commonly derived from classical languages or the Hochdeutsch, which came into contact with Slovenian for the first time in the $16^{\text {th }}$ century. (2) The borrowing language only adopts one of the meanings of the foreign lexeme (semantic narrowing). The first stage of secondary adaptation (secondary semantic change) can occur at the very moment of reception, whereby a narrowing of the semantic field occurs; a lexeme, which originally holds a specialized (most commonly terminological) meaning, receives a more general meaning after determinologization, remaining in general 
use in the $16^{\text {th }}$ century literary Slovenian, e.g. ara - 'a guarantee'. (3) During the second stage of secondary adaptation, the adopted lexeme assumes additional meanings (semantic expansion), which can occur regardless of the original foreign lexeme, e.g. činž (tribute). Translating a foreign lexeme by using the existing native term leads to its semantic expansion towards ambiguity. For instance, the adjective čuden (strange) was used to translate the German lexemes wunderbarlich, wunderlich, unnatürlich, ungewohnt, gar wundersam, seltsam, abscheulich, due to which this adjective holds no less than five meanings and two submeanings in $16^{\text {th }}$ century literary Slovene. Under the dominant influence of the donor language only some lexemes adopted connotative meanings. The analysis concentrates on the expressive use marked by expressive qualifiers ekspr., slabš., iron., evfem., vznes. in the upcoming Dictionary of $16^{\text {th }}$ Century Literary Slovene. Most commonly connotative quality developed towards pejorative meaning, as in the case of some borrowed Christian terms, such as ceremonija (ceremony), menih (monk), nuna (nun), papež (pope), odpustek (pardon) etc. Suffixal diminutives were also influenced by the language of the original (usually German) but to a lesser than expected extent. The analysis of the limited number of examples (from A to D) showed that the morphological diminutive does not necessarily have diminutive semantic meaning, e.g. banderce 'flag' (nem. Fenlin, LB 1545, 1219), cafelc 'an acorn-like object that serves as a cork or pin' (nem. Zapflin, MTh 1603); it also showed that the diminutive suffix was not always adopted under the influence of the original, e.g. ahkerec 'oriel' (nem. Ercker, LB 1545, 1089), človeče (nem. mensch, LH 1566, III, LXIIIIb).

Linguistic analysis has confirmed that the semantic development towards ambiguity in both native lexemes and loanwords is one of the most important reasons for the relatively modest thesaurus of the $16^{\text {th }}$ century literary lexica (just above 22.000 words), which may be attributed not only to the limited functional diversity of the literary lexica but also to the practicality of Protestant writers who, when faced with deficient capacity for reference, expanded the established native and foreign lexemes with new meanings, which proved easier and faster than forming new terms, calquing or excessive borrowing from foreign languages. The use of polysemy for creating denotata, regardless of the donor language influence, reflected the denotative creativity of the Slovene Protestant writers and the expressive potential of Slovene language. 